\title{
A LITHOPHANE MODEL MAKING PROCESS TO 3D PRINTERS
}

\author{
Siddavatam Rammohan Reddy \\ Assistant Professor, Department of Mechanical Engineering, \\ Malla Reddy Engineering College (Autonomous), Telangana, India
}

\begin{abstract}
This paper focuses on to convert photographs into embossed 3D models and then bring them to life using a 3D printer. A Lithophane is a 3-dimensional generation of a 2-dimensional image and $3 D$ representation of a photo can be seen only when it is illuminated from behind. Turning images into $3 D$ objects give us more feeling and literally adds a new dimension. The lithophane can be manufactured by the way of an automated additive manufacturing process, such as 3-D printing. lithophanes are a simple way to enhance your favourite photos. $3 D$ printed photos also known as $3 D$ Printed lithophanes, are an extremely unique and creative application. The process adopted in lithophane is FDM technology, in which different the materials like PLA (polylactic acid), ABS (acrylonitrile butadiene styrene), etc. By heating the filament material to its melting point and it is deposited layer by layer. Combination of many layers will give us a final 3D Printed model.
\end{abstract}

Keywords: Lithophane Printing Process, Lithophane Model,3D Printer, FDM Process \& PLA.

Cite this Article: Siddavatam Rammohan Reddy, A Lithophane Model Making Process to 3D Printers. International Journal of Mechanical Engineering and Technology. 11(5), 2020, pp. 48-53.

https://iaeme.com/Home/issue/IJMET?Volume $=11 \&$ Issue $=5$

\section{INTRODUCTION}

We all know how precious to us the photos and images in our life. transforming these photos into Lithophanes that will light up your image as the lithophane lits up when light passes through it. With 3D Printing Technology today we can easily transform images into a 3D model. 3D printing or additive manufacturing is a process of making three dimensional solid objects from a digital file. In an additive process, an object is created by laying down successive layers of material until the entire object is created.

Rapid prototyping is the fast fabrication of a physical part, model or assembly using 3D Computer Aided Design (CAD). Rapid prototyping technologies are being used in various fields of engineering. These technologies are:
1.Fused deposition modelling (FDM)
2. Stereolithography (SLA)
3.Laminated object manufacturing (LOM)
4.Selective laser sintering (SLS) 
FDM works on an Additive principle of laying down melted material in layers to create objects. Material from the filament spool gets extruded towards the nozzle, heated up and then laid layer over layer to form the 3-Dimensional object. FDM is also known as fused filament fabrication (FFF)

The 3D printers that work on FDM technology consist of the printer platform, a nozzle (also called as printer head) and the raw material in the form of a filament. When the FDM printer begins printing, the raw material is extruded as a thin filament through the heated nozzle. It is deposited at the bottom of the printer platform, where it solidifies. The next layer that is extruded fuses with the layer below, building the object from the bottom up layer by layer. The system sends Design-Specific commands to a controller head, which releases the melted thermoplastic accordingly. This process is repeated layer by layer based on specific design coordinates. The molten material becomes a solid object as soon as it is exposed to a cooler environment.

3D printing significantly challenges mass production processes in the future. This type of printing is predicted to influence industries, like automotive, medical, education, equipment, consumer products industries and various businesses.

\section{LITHOPHANE DESIGN}

Lithophanes can be created in a variety of software tools like 3DP. Rocks, Lithophane maker, Photoshop etc. In this paper, the 3dp.rocks/Lithophane website is preferred because It is simple to use and has 8 different layouts for model design. It makes easy to upload a photo and download a model for 3D printing but for best results, the photo should be edited.

Procedure to be followed:

- Open 3dp.rocks website

- Click on the Images tab and then upload your image. Once the image has been uploaded, it will generate a lithophane model

- Once you return to the Model tab, you'll notice your lithophane is almost ready. You can choose different layouts for your lithophane.

- Select setting tab $\rightarrow$ Model Setting $\rightarrow$ Change parameters like size, Thickness, border etc. $\rightarrow$ click on the model tab and click on Refresh (This would ensure that the print comes out to your preferred dimensions)

- Select setting tab $\rightarrow$ Image Setting $\rightarrow$ Change negative image to positive image $\rightarrow$ click on the model tab and click on Refresh.

- Finally, click "Download" in the Model tab. The browser will download the STL file. 


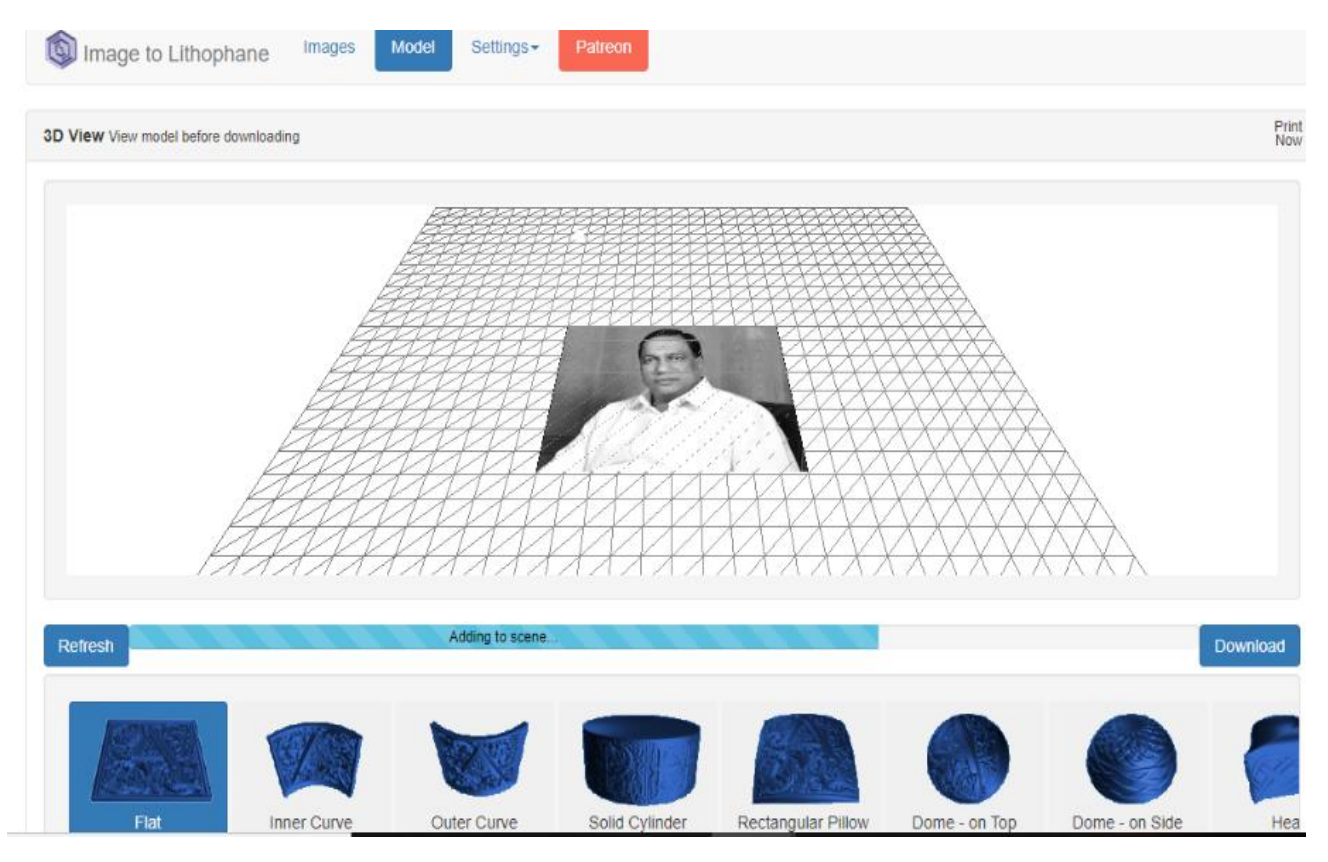

Figure 1 Image Uploading
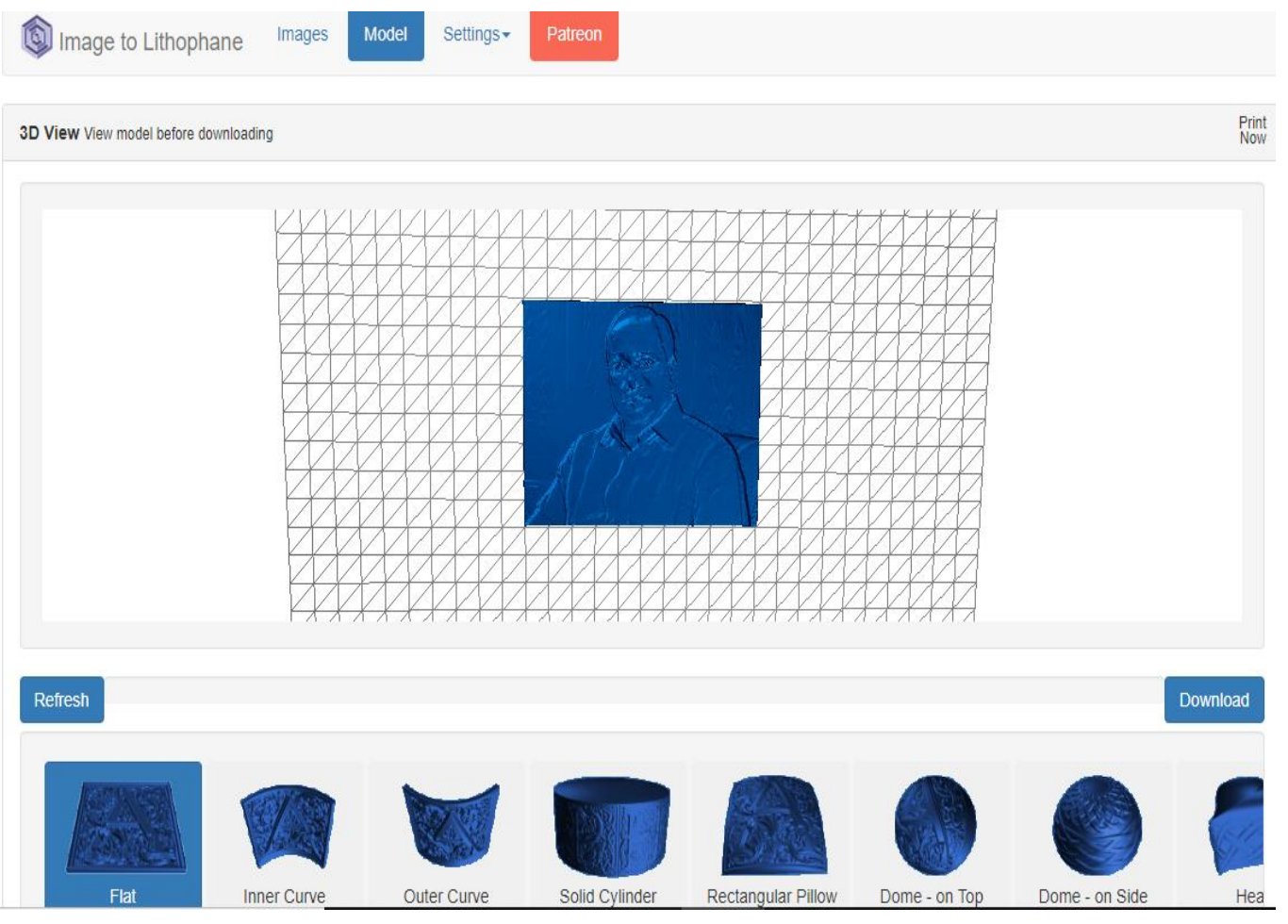

Figure 2 Image to Lithophane Conversion

\section{MODEL SLICING AND GENERATION OF G-CODE}

There are many 3D slicing software's available on the market. these are CURA, Slic3r, idea Maker, Z-Suite, MakerBot Print etc. Cura 3D is one of the many. Cura was developed, hosted and maintained by 3D printer company Ultimaker. Cura is slicing software for 3D printers. The STL or OBJ file can then be imported into the Cura software it is slices model into layers to create a file known as G-Code, which is the code that a 3D printer understands. This GCode is just a text document (in essence) with a list of commands for the 3D printer to read and follow such as hot-end temperature, move to the left this much, right that much etc. 
As every printer has a different setup, print area, build plate and nozzle size, the Cura slicing software needs to know these hardware details in a printer profile. Once it has the required details, you can then specify settings like layer height and thickness. (shown in Table1) Based on the vital stats of the printer and your settings, Cura will calculate the path the printhead needs to take to print your model and produce a list of instructions for the printer. These instructions are saved in that G-Code file. The G-Code can then be saved to an SD card or sent to the printer over wireless or cable depending on the printer directly from Cura.

Steps to be followed:

- Open STL file in CURA by Clicking the "Load" button in the top left-hand corner of the viewport.

- The 3D model appears on the platform.

- Rotate and scale the model as per the requirement by Clicking the respective command icons in the lower left-hand corner of the viewport.

- Select "Save Toolpath" to create G Codes for the part. Save the file that is generated, in an SD card.
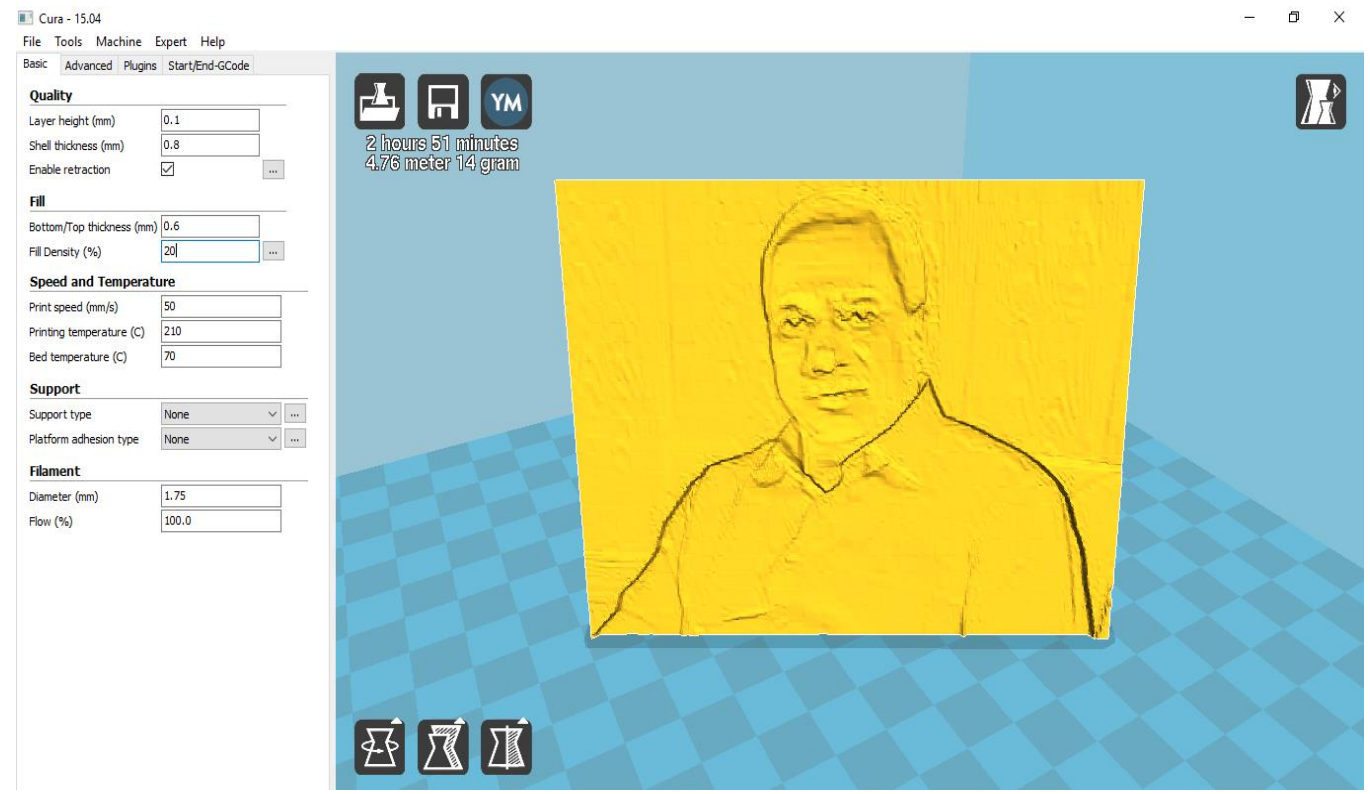

Figure 3 3D Model in CURA

\section{LITHOPHANE PRINTING PROCESS}

3D Printing is the process where liquid molecules, powder or granulated material is solidified and joined to achieve the desired shape and size in three-dimensions. Normally it's done one layer at a time to make sure the proportions of 3D are maintained. 3D printing companies include (Brahma3, Thinl3D, JGroup Robotics,3Ding etc.) those companies that manufacture and distribute 3D printers. Most also offer 3-D printing services and some even conduct training programs for $3 \mathrm{D}$ printing. 3D printing has the power to change the entire industrial landscape because you don't need to make or buy special moulds or tools. 3Ding is one of India's Largest Manufacturer of 3D Printers of the FABX \& Hydra. I used HYDRA- 200 to Print Lithophane. The listed parameters have to enter manually by selecting Machine Tab $\rightarrow$ Add new machine in Cura software. 


$\begin{array}{ll}\text { Specifications } & \text { Hydra 200 Pro } \\ \text { Build Volume } & 200 * 200 * 200 \mathrm{~mm} 3 \\ \text { Bed Temperature } & 70^{\circ} \mathrm{C} \\ \text { Print Speed } & 20-80 \mathrm{~mm} / \mathrm{s} \\ \text { Nozzle size } & 0.4 \mathrm{~mm} \\ \text { Connectivity } & \text { USB, SD Card } \\ \text { Max. Temp. } & 300^{\circ} \mathrm{C} \\ \text { Weight } & 13.5 \mathrm{~kg} \\ \text { Power Consumption } & 60-80 \mathrm{~W} \\ \text { File Type } & \text { STL } \\ \text { Material } & \text { PLA } \\ \text { Software } & \text { Cura } \\ \text { Filament Diameter } & 1.75 \mathrm{~mm}\end{array}$

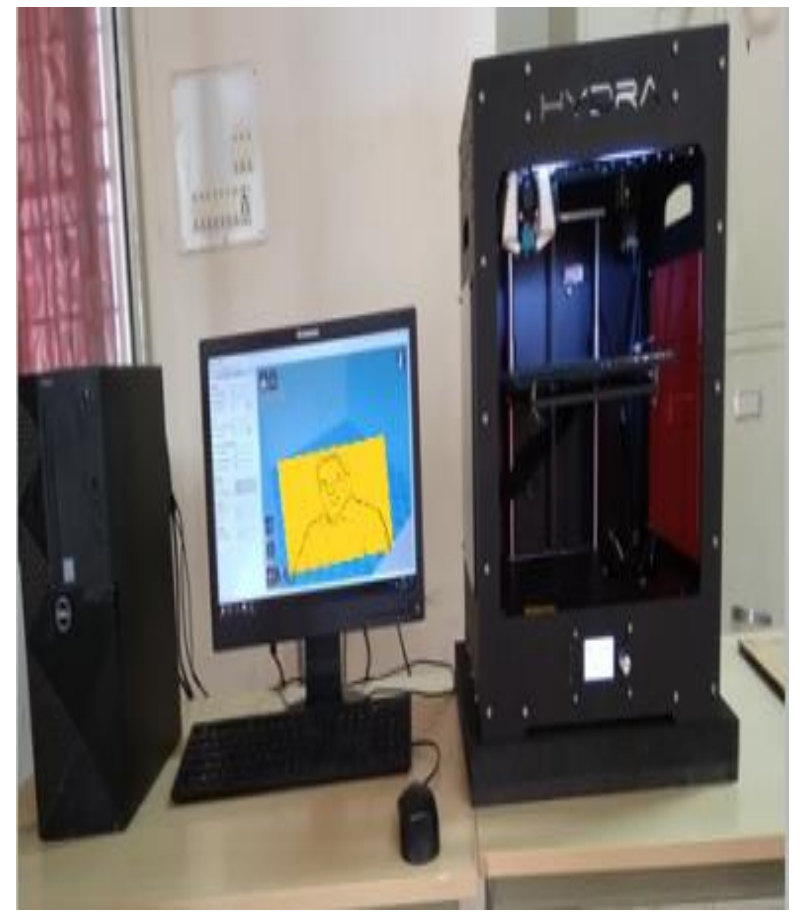

Figure 4 Setup

The following procedure may be used to operate the 3D Printer:

- Switch on the 3D printer and allow it to stabilize. Insert the SD card with the G Code file into the SD port of the printer.

- Press the knob on the 3D printer to get the options. Rotate the knob to scroll the options. Select "Preheat PLA" from display by pressing the knob. Wait to get a pre-set temperature of $210^{\circ} \mathrm{C}$.

- Heating melts the plastic in the nozzle that might have been left from previous work. Use a wire strip to clean and clear the nozzle then Feed the PLA material to the extruder through filler to the nozzle.

- Remove and clean the magnetic plate. Fix the plate on bed and adjust the height if necessary.

- Press the knob to navigate through options and select "Print from SD". Choose the G Code file from SD to be printed. 3D printer will heat the bed automatically and return to the home position. This process may take a few minutes.

- Now, 3D Printer prepares the model and start printing. Wait till the completion of a model on the bed. After model printing, select "Disable Steppers" by using the knob and Rotate the middle slider of the bed to lower the bed.

- Remove the magnetic plate from the bed and Use a knife or a sharp tool to remove the model from the plate.

There are a number of variables that can affect your lithophane including the filament used, model thickness, slicer settings and light source. You can experiment by printing multiple lithophanes and adjusting the z-height. 


\section{3D PRINTED LITHOPHANE}

The printed lithophane is shown below. I have printed a photo of my Chairman Sri. Ch. Malla Reddy Garu. It looks like a flat piece of plastic with a few scratches on it, but put it in front of a light source like the sun, and you'll see an image.

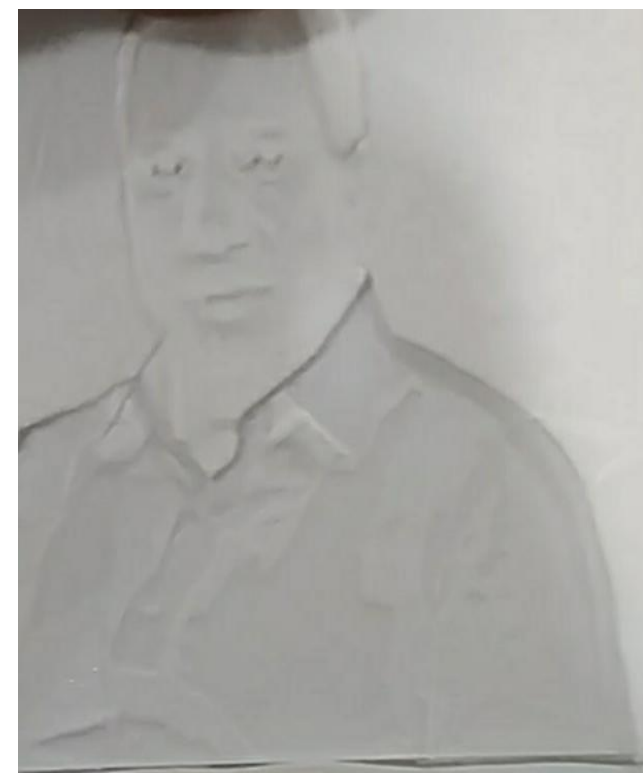

Figure 5 LIGHT OFF

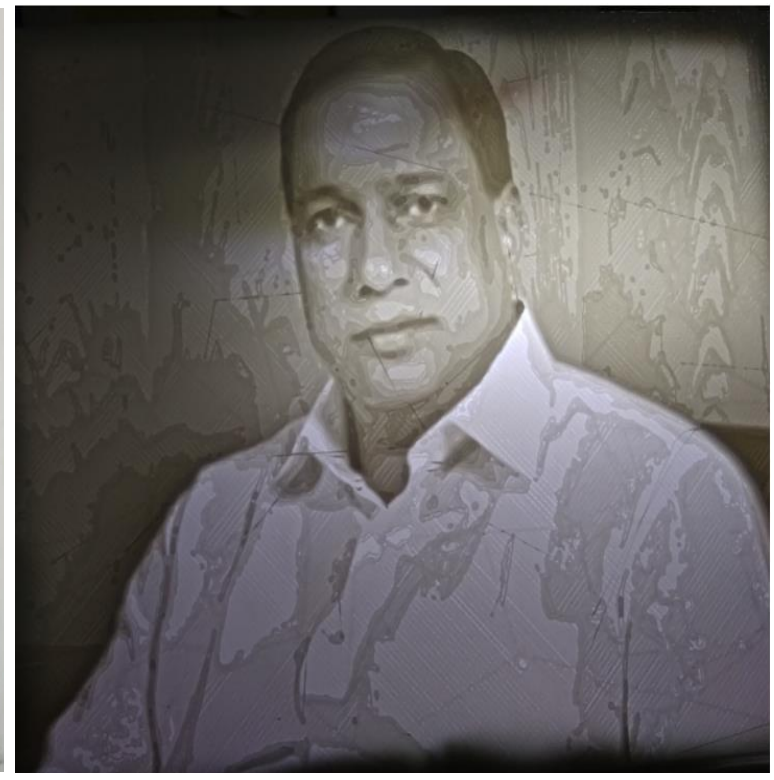

Figure 6 LIGHT ON

\section{CONCLUSION}

$3 \mathrm{D}$ printing significantly challenges mass production processes in the future. This type of printing is predicted to influence industries, like automotive, medical, education, equipment, consumer products industries and various businesses.

\section{REFERENCES}

[1] 3dp.rocks/lithophane/

[2] https://pinshape.com/blog/3-steps-creating-lithophanes/

[3] https://all3dp.com/1/cura-tutorial-software-slicer-cura-3d/

[4] https://www.3ding.in/3dprinters/

[5] T. Prabhu (2016), Modern Rapid 3D printer- A Design Review, International Journal of Mechanical Engineering and Technology,

[6] A Ramya and Sai leela Vanapalli, 3d Printing Technologies in Various Applications. International Journal of Mechanical Engineering and Technology, 7(3), 2016,

[7] https://www.instructables.com/id/How-to-3D-Print-a-Photo-Lithophanes-101/

[8] https://all3dp.com/2/howto-3d-print-your-own-lithophane/

[9] https://studiofathom.com/blog/4-steps-to-3d-printed-photography

[10] https://www.researchgate.net/publication/335174416_An_Overview_on_3D_Printing_Tec hnology_Technological_Materials_and_Applications

[11] https://thestempedia.com/tutorials/converting-image-to-lithophane/

[12] https://techwiser.com/create-your-own-3d-printed-lithophanes/

[13] https://www.youtube.com/watch?v=y63sVpeViXo 